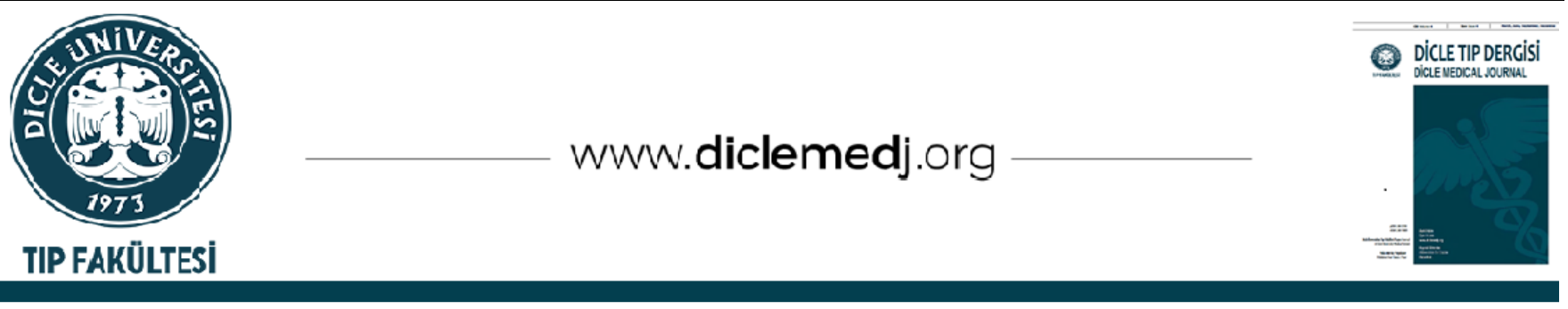

\title{
Obsesif Kompulsif Bozuklukta Travmatik Yaşantılar
}

\author{
Sevda Korkmaz ${ }_{1}$, Sema Baykara $D_{1}$, Mehmet Gürkan Gürok $\mathrm{D}_{1}$, Şüheda Kaya $\mathrm{iD}_{2}$, Gülay Taşçı $\mathrm{iD}_{3}$, \\ Murad Atmaca 1
}

1 Fırat Universitesi Tıp Fakültesi Psikiyatri Kliniği, Elazı̆̆, Türkiye

2 Elaziğ Ruh Sağlı̆̆ı ve Hastalıkları Hastanesi, Elazı̆̆, Türkiye

3 Fethi Sekin Şehir Hastanesi, Elazı̆̆, Türkiye

Geliș: 28.07.2020; Revizyon: 27.09.2020; Kabul Tarihi: 12.10.2020

\section{Öz}

Amaç: Bu çalışmada, obsesif kompulsif bozukluğu olan hastaların geçmiş yaşam öykülerindeki travmatik yaşantılarının varlığı ve bunların obsesyon ve kompulsiyon türleri ile olabilecek ilişkisinin araştırılması amaçlanmıştır.

Yöntemler: Son 3 ay içerisinde psikiyatri polikliniğine başvuran ve çalışma ölçütlerine uyan, obsesif kompulsif bozukluk (OKB) tanısı almış, 48 hasta çalışmaya dahil edildi. Hastalara Eksen I Bozuklukları için Yapılandırılmış Görüşme Çizelgesi (SCID-5), Yale-Brown Obsesyon Kompulsiyon Derecelendirme Ölçeği (Y-BOCS), Beck Depresyon Ölçeği (BDÖ) ve Travmatik Yaşantılar Ölçeği (TEC) uygulandı. İstatistiksel analizler için SPSS versiyon 22 paket programı kullanıldı. Testler arasında pozitif ya da negatif bir ilişkinin olup olmadığı Pearsen korelasyon analizi yapılarak değerlendirildi. $\mathrm{p}<0.05$ değerleri istatistiksel olarak anlamlı kabul edildi.

Bulgular: Çalışmaya 32'si kadın, 16'sı erkek olmak üzere toplam 48 OKB hastası dahil edildi. Hastaların yaş ortalaması $35.1 \pm 10.9$ idi. Örneklemin ortalama Y-BOCS toplam puanı $23.7 \pm 8.5$, BDÖ toplam puanı $23.7 \pm 12.7$ idi. Örneklemin 33 tanesinde bir ya da daha fazla travma öyküsü bulunmaktaydı. Hastaların 17'sinde duygusal ihmal, 19'da duygusal istismar, 18'de bedensel istismar, 3'ünde cinsel taciz/cinsel istismar olduğu belirlendi. Hastalı̆̆ın başlangıç yaşıyla travma sayısı arasında negatif bir korelasyon bulunmaktaydı ( $\mathrm{p}=0.26 \mathrm{r}=-3.21$ ). Obsesyonlar, otojen ve reaktif olarak ikiye ayrıldı̆̆ında, otojen obsesyonları olan hastaların travma sayısı ve total travma puanları, reaktif obsesyonları olan hastalardan anlamlı derecede yüksek bulundu $(\mathrm{p}=0.037, \mathrm{p}=0.041)$.

Sonuç: Çalışmamızda OKB hastalarının çok büyük bir kısmının geçmişinde en az bir ya da daha fazla travmatik yaşantının olduğu belirlendi. Yine travma sayısı arttıkça hastalık belirtilerinin daha erken yaşlarda ortaya çıkacağı saptandı. Otojen obsesyonları olan hastaların travma sayısı ve total travma puanları reaktif obsesyonları olan hastalardan anlamlı derecede yüksek bulundu.

Anahtar kelimeler: Obsesyon, kompulsiyon, travma

DOI: 10.5798/dicletip.850486

Correspondence / Yazışma Adresi: Sevda Korkmaz, Fırat Universitesi Tıp Fakültesi Psikiyatri Kliniği, Elazığ, Türkiye e-mail : skorkmaz23@hotmail.com 


\title{
Traumatic Experiences In Obsessive Compulsive Disorders
}

\begin{abstract}
Objective: The aim of this study is to investigate the presence of traumatic experiences in patients with obsessive-compulsive disorder and their relationship with obsession and compulsion types.

Methods: Forty-eight patients who were admitted to psychiatry outpatient clinic within the last 3 mounths and diagnosed with obsessive-compulsive disorder (OCD) were included in the study. The patients were administered a Structured Interview Schedule for Axis I Disorders (SCID-5), Yale-Brown Obsessive-Compulsive Scale (Y-BOCS), Beck Depression Inventory (BDI) and Traumatic Experiences Scale (TEC).

Results: A total of 48 OCD patients; 32 to be female and 16 to be male were included in the study. The mean average of the patients' age was $35.1 \pm 10.9$. The mean total Y-BOCS score of the sample was $23.7 \pm 8.5$, and the BDI score was $23.7 \pm 12.7$. Thirty three of the sample had either one or more trauma history. There was a negative correlation between the age of onset of the disease and the number of trauma $(\mathrm{p}=0.26 \mathrm{r}=-3.21)$. Patients with autogenous obsessions were significantly higher than those with reactive obsessions $(\mathrm{p}=0.037, \mathrm{p}=0.041)$.

Conclusion: In our study, it was determined that most of OCD patients had one or more traumatic experiences in their early life. It was revealed that as the number of traumas increased, the disease symptoms would appear at an earlier age and that the number of trauma and total trauma scores of patients with autogenous obsessions were significantly higher than those with reactive obsessions.
\end{abstract}

Keywords: Obsession, compulsion, trauma.

\section{GíRiş}

Obsesif-kompulsif bozukluk (OKB), önemli alanlarda kişilerin işlevselliğini bozan ve zihnini sürekli meşgul eden obsesyon ve kompulsiyonlarla karakterize olan bir hastalıktır (Mental Bozuklukların Tanısal ve Sayımsal El Kitabı). OKB'nin etiyolojik nedenleri arasında genetik ve biyolojik nedenler, beyin işlevlerinde bozulma, kişilik özellikleri önemli derecede rol oynamaktadır. Son zamanlarda erken çocukluk döneminde karşılaşılan travmatik olayların ve stresli durumların da OKB'ye yatkınlık oluşturabileceği görüşü üzerinde durulmaya başlanmıştır ${ }^{1,2}$. Özellikle yaşanan travmatik olay sonrasında, düşünceler üzerinde olumsuz değerlendirmeler yapılmasının OKB belirtilerini arttırabileceği düşünülmektedir. Yine travmatik olay ile ilgili düşüncelerin olumsuz yorumlanması ile ortaya çıkan kaygı ve stresi azaltmak için de bazı bireylerin kompulsif ritüeller geliştirebileceği bildirilmiştir ${ }^{3}$. Literatürde OKB ve çocukluk çağ travmaları arasındaki ilişkiyi incelenmek amacıyla çeşitli araştırmalar yapılmıştır ${ }^{4-7}$. Ancak dizinde, obsesyon ve kompulsiyonun türleri ile travma alt tipleri arasındaki ilişkiyi incelemeyi amaçlayan sınırlı sayıda çalışma bulunmaktadır8,9. Obsesif kompulsif bozuklukta obsesyon ve kompulsiyonlara ait içeriklerin farklı olmasina neden olan etiyolojilerin belirlenmesi önem arzetmektedir. Klinik gözlemlerimize göre genellikle belirli bir uyaran olmaksızın zihne gelen otojen obsesyonlar ile bir dış uyaranla ortaya çıkan ve daha gerçekçi olan reaktif obsesyonların etiyolojisinde değişik faktörler rol oynayabilir. Bu alanda yapılacak olan yeni çalışmalar ihtiyaç olduğu düşünülmektedir. Yaptığımız bu çalışmada, obsesif kompulsif bozukluğu olan hastaların geçmiş yaşam öykülerindeki duygusal istismar, ihmal, fiziksel istismar ve cinsel istismar gibi travmatik yaşantılarının varlığı ve bunların obsesyon ve kompulsiyon türleri ile olabilecek iliş̧isinin araştırılması amaçlanmıştır.

\section{YÖNTEMLER}

$\mathrm{Bu}$ vaka kontrol çalışmamız için Fırat Üniversitesi Tıp Fakültesi Girişimsel Olmayan Araştırmalar Etik Kurulundan 19/11/2018 tarihli, 294354 sayılı yazısı ile onay alındı ve helsinki bildirgesine uygun olarak çalışma 
yürütüldü. Çalışmaya Aralık 2018-Şubat 2019 tarihleri arasında Firat Üniversitesi Hastanesi Ruh Sağlığı ve Hastalıkları Polikliniğine başvuran, Mental Bozuklukların Tanısal ve Sayımsal El Kitabı (DSM 5)'e göre OKB tanısı konmuş, 18-65 yaşlar arası 55 hasta ile görüşüldü. Hastalardan OKB'ye eşlik eden başka bir DSM-5 bozukluğunun olmaması nörolojik bir hastalığın olmaması var olan psikiyatrik belirtilerin dağılımını etkileyecek herhangi bir önemli bedensel patolojinin veya herhangi bir bedensel hastalığın olmaması şartları arandı. Depresyon ve anksiyete bulguları OKB'ye çok sık eşlik edebileceği için, bu semptomlar dışlama kriterleri arasında değerlendirilmedi. Son 6 ay içerisinde alkol ve madde kötüye kullanımı ya da madde bağımlılığı öyküsü olma dışlama kriteri olarak kullanıldı. 2 hasta çalışmaya katılmayı kabul etmediği için, 3 hastanın yakın geçmişinde madde kullanım öyküsü olduğu için, 2 hastada ise sorulara cevap vermeyi engelleyecek düzeyde bilișsel fonksiyon bozukluğu belirlendiği için bu hastalar çalışma dışı bırakıldı. Çalışmaya toplam olarak 48 hasta alındı. Poliklinikte görevli iki psikiyatri uzmanı tarafından hastaların yaş, medeni durum, eğitim durumu, meslek, cinsiyet, yaşanılan yer, ekonomik durum gibi sosyodemografik bilgileri tarafımızca hazırlanan sosyodemografik veri formuna kaydedildi. Hastalara DSM-5 için Yapılandırılmış Klinik Görüşme (SCID-5-CV) Çizelgesi, Yale-Brown Obsesyon Kompulsiyon Derecelendirme Ölçeği (Y-BOCS), Beck Depresyon Ölçeği ve Travmatik Yaşantılar Ölçeği (TEC) uygulandı.

\section{Çalışmada Kullanılan Ölçekler:}

DSM-5 Bozuklukları için Yapılandırılmış Klinik Görüşme Çizelgesi (SCID-5-CV) DSM-5 için Yapılandırılmış Klinik Görüşme çizelgesi, DSM5 tanılarını koymak için geliştirilmiş, yarı yapılandırılmış bir görüşme kılavuzudur. Türkçeye uyarlanması ve güvenilirlik çalışması Elbir ve arkadaşları tarafından yapılmıştır ${ }^{10}$.
Yale-Brown Obsesyon Kompulsiyon Derecelendirme Ölçeği (Y-BOCS) OKB tanılı hastalarda obsesif kompulsif belirtilerin türü ve şiddetini ölçmek amacıyla geliştirilmiş, klinisyen tarafından uygulanan yarı yapılandırılmış bir ölçektir. Goodman ve arkadaşları tarafından geliştirilen bu ölçek toplam 19 maddeden oluşur ${ }^{11}$. Ölçekte, obsesyon ve kompulsiyonlar beșer madde ile ve her bir madde dört puan üzerinden olmak üzere ayrı ayrı puanlanmakta, obsesyon ve kompulsiyon alt toplam puanları ve sonunda en fazla 40 puan üzerinden toplam bir puan elde edilmektedir. Türkçe uyarlaması Karamustafalıŏlu ve arkadaşları tarafından yapılmıștır ${ }^{12}$.

\section{Travmatik Yaşantılar Ölçeği (TEC)}

Bu ölçek, duygusal ihmal, duygusal istismar, ebeveynlik, olağanüstü aile yüklülüğü, yoksulluk, psikiyatrik hastalık, alkolizm veya ebeveynin uyușturucu bağımlılı̆ııı sorgulayan 29 sorudan oluşan bir kendi kendini değerlendirme ölçeğidir. Nijenhuis ve arkadaşları tarafından 2002 yılında geliştirilmiştir ${ }^{13}$. Ölçeğin Türkçe geçerlik ve güvenirlik çalışması 2000 yılında Şar tarafından yapılmıștır'14. TYÖ'nin 4 haftalık test-retest güvenilirliği $(r=0.91)$ ve geçerliliği kadar iç tutarlılığı da (Cronbach-test $=0.86$, retest $=$ 0.90) oldukça iyi bulunmuştur. Ölçek kişinin başından geçen travmatik olayları, olay sırasında kaç yaşında olduğunu ve olayın kşiyi ruhsal açıdan ne kadar etkilediğini sorgulamaktadır. Ölçekte kişi olayı yaşadıysa 1 puan, yaşamadıysa 0 puan verilir. TEC total skoru muhtemel travmatik yaşantıların sayısını gösterir (aralık 0-29). Ayrica her travma tipi (duygusal ihmal, duygusal istismar, bedensel istismar, cinsel taciz, cinsel istismar) için detaylı olarak bileşik puanlar hesaplanabilmektedir. Duygusal ihmal; 14,15,16, duygusal istismar; 17,18,19, fiziksel istismar; 9,10, 20,21,22,23, cinsel taciz; $24,25,26$ ve cinsel istismar; $27,28,29$. Sorularından elde edilen sonuçların 
toplamı şeklinde hesaplanır. Tüm travma çeşitlerine ait toplam travma bileşik puan aralığı 0-69 aralığındadır.

\section{Beck Depresyon Ölçeği (BDö)}

Erişkinlerde depresyon riskini, depresif belirtilerin şiddet değişimini ve düzeyini ölçmek üzere 1961'de Beck tarafından geliştirilmiştir ${ }^{15}$. Türkçe geçerlik ve güvenirlik çalışması 1989 yılında Hisli tarafından yapılmıştır ${ }^{16}$. Güvenilirlik çalışmasında , Cronbach alfa katsayısı 0,80 olarak bulunmuştur. Depresyon çalışmalarında sıkça kullanılır ve 21 maddelik likert tipi kendini değerlendirme ölçeğidir. Her madde depresyonla ilgili davranışsal bir özellikle ilgilidir. Maddeler, depresyonun ciddiyetine göre 0-3 arası puanlarla puanlanır. Toplam puan 0-63 arasında değişir. Alınan puan 0-9 arasında ise depresif belirtiler olmadığını, 1016 puan hafif, 17-24 puan orta, 25 ve üzeri puan şiddetli düzeyde depresif belirtiyi göstermektedir. Ölçeğin kesme puanı 17 olarak belirlenmiştir.

\section{İstatiksel Yöntem}

Mevcut veriler literatür eşliğinde değerlendirildi. Çalışmada elde edilen bulgular değerlendirilirken, istatistiksel analizler için SPSS (Statistical Package for Social Sciences) for Windows 22 paket programı kullanıldı. Verilerin analizinde; frekans (f), yüzde (\%), aritmetik ortalama ( X ), standart sapma (Ss) hesaplanmıştır. Bağımlı ve bağımsız değişkenler arasındaki ilişkinin anlamlı olup olmadığını test etmek amacıyla pearson korelasyon testi kullanıldı. $\mathrm{p}<0.05$ değerleri istatistiksel olarak anlamlı kabul edildi.

\section{BULGULAR}

Çalışmaya 32'si kadın, 16'sı erkek olmak üzere toplam $48 \mathrm{OKB}$ hastası dahil edildi. Hastaların yaş ortalaması $35.1 \pm 10.9$ idi. Örneklemin ortalama Y-BOCS toplam puanı $23.7 \pm 8.5$, BDÖ toplamı 23.7 \pm 12.7 , TEC toplam puanı idi (Tablo
1). BDÖ 'de 17 puan kesme puanı olarak kabul edildiğinde, hastaların 30 'unda (\%63) depresyon olduğu belirlendi. Yapılan korelasyon analizinde, YBOCS puanları ile depresyon puanları arasında pozitif bir ilişki saptandı. Ancak aynı ilişki diğer ölçekler arasında saptanmadı (Tablo 2). İntihar girişimi hastaların 10 da bulunmaktaydı. Hastalarda kirlenme $(\% 65)$ ve cinsel obsesyonlar $(\% 54,2)$ en fazla görülen obsesyonlar iken, temizlik/yıkanma $(\% 65,3)$ kompulsiyonları ile kontrol $(\% 14,3)$ kompulsiyonları en sık görülen kompulsiyonlardı. Örneklemin 33 tanesinde bir ya da daha fazla travma öyküsü bulunmaktaydı. Hastaların 17 de duygusal ihmal, 19 da duygusal istismar, 18 de bedensel istismar, 3 tanesinde cinsel taciz/cinsel istismar belirlendi. Hastaların \%78 'inin ya şikayetleri olaydan sonra başlamıştı ya da daha önce varolan şikayetleri olay sonrasında artmıştı. Hastalığın başlangıç yaşıyla travma sayısı arasında negatif bir korelasyon bulunmaktayd $(\mathrm{p}=0.26 \mathrm{r}=-3.21)$. Cinsel, dini ve agresyon temaları ile ilgili obsesyonu olan hastalar otojen, kirlenme-bulaşma, simetri-düzen ve somatik temaları içeren obsesyonları olan hastalar reaktif grup olarak ikiye ayrıldı. Otojen obsesyonları olan hastaların $(n=10)$ total travma puanları reaktif obsesyonları olan hastalardan $(\mathrm{n}=38)$ anlaml derecede yüksek bulundu ( $\mathrm{p}=0.041)$ (Tablo 3). İntihar girişiminde bulunan hastaların \%80'de, intihar öyküsü olayan hastaların ise $\% 66$ 'da en az 1 yada daha fazla travma hikayesi bulunmaktaydı.

Tablo I: Katılımcıların ölçek puanları ortalaması

\begin{tabular}{|l|l|}
\hline & mean \pm std.d \\
\hline BDÖ & $23.7 \pm 12.7$ \\
\hline Y-BOCS & $23.7 \pm 8.5$ \\
\hline Duygusal ihmal & $2.69 \pm 4.2$ \\
\hline Duygusal istismar & $2.31 \pm 3.53$ \\
\hline Fiziksel istismar & $2.5 \pm 3.85$ \\
\hline Cinsel taciz & $0.19 \pm 0.73$ \\
\hline Cinsel istismar & $0.23 \pm 0.9$ \\
\hline TEC toplam & $7.96 \pm 8.37$ \\
\hline
\end{tabular}

BDÖ= Beck depresyon ölçeği $Y$-BOCS= Yale-Brown Obsesyon Kompulsiyon Derecelendirme Ölçeği, TEC=Travmatik Yaşantılar Ölçeği 
Tablo II: Ölçekler arasında korelasyon analizi

\begin{tabular}{|c|c|c|c|c|c|}
\hline & & $\begin{array}{c}\text { TEC } \\
\text { Toplam } \\
\text { puanı }\end{array}$ & BDÖ & Y-BOCS & $\begin{array}{c}\text { Toplam } \\
\text { travma } \\
\text { sayısı }\end{array}$ \\
\hline \multirow{2}{*}{$\begin{array}{l}\text { TEC Toplam } \\
\text { puanı }\end{array}$} & $r$ & 1 & ,257 & ,049 & $686^{* *}$ \\
\hline & $p$ & &, 078 & ,739 &, 000 \\
\hline \multirow{2}{*}{ BDÖ } & r &, 257 & 1 &, $548^{* *}$ & ,189 \\
\hline & $p$ & ,078 & &, 000 & ,199 \\
\hline \multirow{2}{*}{ Y-BOCS } & $r$ & ,049 &, $548^{* *}$ & 1 &,- 098 \\
\hline & $p$ & ,739 &, 000 & &, 507 \\
\hline \multirow{2}{*}{$\begin{array}{l}\text { Toplam } \\
\text { travma sayısı }\end{array}$} & $r$ &, $686^{* *}$ & ,189 &,- 098 & 1 \\
\hline & $p$ & ,000 & ,199 & ,507 & \\
\hline
\end{tabular}

Tablo III: Otojen ve reaktif obsesyonlu hastaların ölçek puanlarının karşılaştırılması

\begin{tabular}{|l|l|l|l|}
\hline & $\begin{array}{l}\text { Otojen } \\
\text { obsesyon } \\
\text { grubu (n=10) }\end{array}$ & $\begin{array}{l}\text { Reaktif obsesyon } \\
\text { grubu (n=38) }\end{array}$ & $\mathrm{p}$ \\
\hline BDÖ & $25.6 \pm 8.85$ & $23.24 \pm 13.63$ & 0.514 \\
\hline Y-BOCS & $22.7 \pm 9.68$ & $23.92 \pm 8.24$ & 0.721 \\
\hline $\begin{array}{l}\text { Total } \\
\text { Travma } \\
\text { Puanı }\end{array}$ & $13.1 \pm 8.03$ & $6.71 \pm 7.9$ & $0.041^{*}$ \\
\hline
\end{tabular}

${ }^{*} p<0.05,{ }^{* *} p<0.001, B D O ̈=$ Beck depresyon ölçeği $Y$-BOCS= Yale-Brown Obsesyon Kompulsiyon Derecelendirme Ölçeği

\section{TARTIŞMA}

Çalışmamızda, obsesif kompulsif bozukluğu olan hastaların büyük br çoğunluğunda (\%69), bir ya da daha fazla çocukluk çağı travma öyküsü olduğu ve hastalığın başlangıç yaşıyla travma sayısı arasında negatif bir ilişki olduğu belirlenmiştir. Çocuğa kötü muamele, ebeveynler, diğer yetişkinler ya da akranlar tarafindan bilmeyerek ya da kasti olarak yapılan, normlara uymayan ve çocuğun fiziksel ya da duygusal olarak zarar görmesine neden olan veya çocuğun ihtiyaçlarının karşılanması için yapılması gerekli olduğu halde yapılmayan davranışları içermektedir ${ }^{17}$. Gelişim dönemlerinin ilk yıllarında geçirilen travmatik olaylar, duygusal, fiziksel, bilişsel, davranışsal ve sosyal alanlarda çocuğun beyin yapısını, gelişimini olumsuz yönde etkileyerek, hem çocukluk hemde yetişkinlik döneminde birçok psikiyatrik hastalığın oluşmasına zemin hazırlamaktadır ${ }^{18}$.

Yaşamın erken döneminde maruz kalınan şiddetli stresin, depresyon, anksiyete ve madde kullanımı gibi birçok psikiyatrik bozukluğu ortaya çıkardığı bildirilmiştir ${ }^{19}$. çocukluğunda kötü muameleye maruz kalanların daha fazla depresyon ve kaygı belirtileri gösterdikleri, hayat boyu alkol problemi yaşama olasılıklarının arttığı belirtilmiştir ${ }^{20}$. Yine bu travmaların $\mathrm{OKB}$ ve suisid riski ile ilişkili olabileceği üzerinde duran çalışmalar bulunmaktadır ${ }^{21}$.

Literatürde, OKB'nin ortaya çlkmasında istismar, yaşamsal değişiklikler, hastalıklar, çok sevilen birisinin ölümü, ilişkilerde yaşanan endişe gibi travmatik yaşantıların çevresel bir faktör olarak rol oynadığ bildirilmiştir ${ }^{22}$. Çocuklukta yaşanan travmatik deneyimlerin, stresle tetiklenen olumsuz girici düşüncelerin sıklığını ve yoğunluğunu artırabileceği, hastalığın klinik semptomlarına yol açarak, obsesif kompulsif bozukluğun etiyolojisinde rol oynayableceği düşünülmüştür ${ }^{23}$. Çocukluğunda kötü muameleye maruz kaldığını düşünen kişilerin kişisel olmayan dünya, kendileri ve diğerleriyle ilgili olumsuz varsayımları bulunmaktadır ${ }^{24}$. Ayrıca bu yaşantılar; obsesif inanışlar ve obsesif-kompulsif belirtilerle ilişkili olan abartılı sorumluluk algısı gelişiminde ve tehdit algılarının hassaslaşmasında etkili olmaktadır ${ }^{25}$. Yapılan bir çalışmada, OKB tanısı almış kişilerde herhangi bir psikiyatrik tanı almamış kişilere göre çocukluk çağı travmatik yaşam olaylarının daha yüksek oranda görüldüğü bildirilmiştir ${ }^{26}$. Çalışmamızda, okb 
tanısı almış bireylerde yüksek oranda değerlendirdiğimiz travma sayısı ve travma skorları yüksekliği literatürde bildirilen bulguları destekler niteliktedir.

Çalışmamızda, otojen obsesyonları olan hastaların (cinsel, dini, agresyon temalı obsesyonlar) total travma puanları reaktif obsesyonları olan hastalardan (kirlenmebulaşma, simetri-düzen ve somatik temaları içeren obsesyonlar) anlamlı derecede yüksek bulunmuştur. Otojen obsesyonlar genellikle belirli bir uyaran olmaksızın zihne gelen ve benliğe yabancı olan obsesyonlar olarak bilinmektedir. Reaktif obsesyonlar ise bir dış uyaranla ortaya çıkan ve daha gerçekçi olan obsesyonlardir ${ }^{27}$. Otojen obsesyonlar daha tekrarlayıcı, daha fazla rahatsız edici, kişinin kendisinde bulunmasindan daha fazla rahatsızlık duyabileceği, hakkında daha az konuşulmak istenen ve zihinde belirmesi için daha az uyarana ihtiyaç duyulan obsesyonlardır28. $\mathrm{Bu}$ obsesyonları olan bireylerde, düşünce bozukluğuna daha sık rastlandığı ve antipsikotik tedaviye daha fazla maruz kaldıkları da öne sürülmektedir ${ }^{29}$. Çalışmamızda belirlediğimiz otojen obsesyonlu hasta grubundakı yüksek travma skorlarının, bu düşünce bozukluğuna ve olumsuz başa çıkma yöntemlerinin kullanılmasına bir katkısı olabilir.

Literatürde, travmanın türleri (duygusal istismar, ihmal, fiziksel istismar ve cinsel istismar) ile obsesyon ve kompülsiyonlar arasındaki ilişkiyi incelemeyi amaçlayan bazı çalışmalar bulunmaktadır ${ }^{30}$. Yapılan bu çalışmalarda, fiziksel istismarın, cinsel istismarın bazılarında ise duygusal ihmal ve istismarın ${ }^{1,4,27}$ OKB belirtileriyle ilişkili olduğu ortaya konulmuştur. Bizim çalışmamızda da hastaların \%78 'inin ya şikayetleri olaydan sonra başlamıştı ya da daha önce varolan şikayetleri olay sonrasında artmıştı. Yine, duygusal ihmal, duygusal istismar ve bedensel istismar bu hasta grubunda en sık karşılaşılan travma türleri olmuştur. Ancak örneklem sayımızın nisbeten sınırlı olması, ve çoğu kişide birden fazla travma türünün yaşanmıș olması, travma türleri ile belirtiler arasındaki ilişkinin sayısal değerlerle ortaya konulmasına engel olmuş olabilir.

\section{SONUÇ}

Sonuç olarak çalışmamız, travmatik yaşantıların OKB belirtilerinin ortaya çıkmasında ve obsesyon türlerinin farklılaşmasında etkili olabileceğini göstermiştir. Ancak ilerde daha büyük bir örneklem üzerinde kontrol grubu kullanılarak yapılan geniş çaplı araştırmalarla bu bulgularımızın desteklenmesi gerekmektedir.

Çalışmamızın birtakım kısıtlılıkları bulunmaktadır. Örneklem sayısının nispeten küçük olması ve kontrol grubunu olmaması bu kısıtlılıklardan sayılabilir. Yine çalışmada kullanmış olduğumuz tüm ölçekler öz bildirim ölçekleridir. Bazı katılımcıların geçmiş yaşantılarına ait hassas konuları başkası ile paylaşmaktan rahatsızlık duyacakları için, bu konularda verdikleri cevaplar bireylerin kişilik özelliklerine bağlı olarak değişebilmektedir. Bu durum, belki de sayı olarak daha fazla ve sıkıntı verici özelliği daha yoğun olabilecek bazı olumsuz yaşantıların dile getirilmemesine neden olmuş olabilir.

Etik Kurul Onayı: Bu vaka kontrol çalışmamız için Fırat Üniversitesi Tıp Fakültesi Girişimsel Olmayan Araştırmalar Etik Kurulundan 19/11/2018 tarihli, 294354 sayılı yazısı ile onay alındı ve helsinki bildirgesine uygun olarak çalışma yürütüldü.

Çıkar Çatışması Beyanı: Yazarlar çıkar çatışması olmadığını bildirmişlerdir.

Finansal Destek: Bu çalışma her hangi bir fon tarafından desteklenmemiştir.

\section{KAYNAKLAR}

1. Akpınar A, Bakım B, Alpak G, ve ark. Cinsel obsesyonlarla seyreden obsesif-kompulsif 
bozukluklarda çocukluk çağı travması, cinsel işlevler, psikiyatrik komorbidite ve sosyodemografik veriler. Dicle Tıp Dergisi. 2013; 40: 183-91.

2. Ay R, Erbay LG. Relationship between childhood trauma and suicide probability in obsessivecompulsive disorder. Psychiatry Res. 2018; 261: 132-6.

3. Rachman S. A cognitive theory of compulsive checking. Behavior Research and Therapy. 2002; 40: 625-39.

4. Semiz UB, Inanc L, Bezgin CH. Are trauma and dissociation related to treatment resistance in patients with obsessive-compulsive disorder? Social Psychiatry and Psychiatric Epidemiology. 2014; 49: 1287-96.

5. Lochner C, Sedat S, Hemmings SM, et al. Dissociative experiences in obsessive-compulsive disorder andtrichotillomania: clinical and genetic findings. Compr Psychiatry. 2014; 45: 384-91.

6. Caspi A, Vishne T, Sasson Y, et al. Relationship between childhood sexual abuse and obsessive compulsive disorder: case control study. Isr J Psychiatry Rel Sci. 2008; 45: 177-82.

7. Tibi L, Van Oppen P, Van Balkom AJLM, et al. Childhood trauma and attachment style predict the four-year course of obsessive compulsive disorder: Findings from the Netherlands obsessive compulsive disorder study. J Affect Disord. 2020; 264: 206-14.

8. Demirci K. Çocukluk Çağı Travmaları ve Obsesif Kompulsif Belirtilerin İlişkisinin İncelenmesi. Journal of Mood Disorders (JMOOD). 2016; 6: 7-13.

9. Badour CL, Bown S, Adams TG, Bunaciu L, Feldner MT. Specificity of fear and disgust experienced during traumatic interpersonal victimization in predicting posttraumatic stress and contaminationbased obsessive-compulsive symptoms. Journal of Anxiety disorders. 2012; 26: 590-8.

10. Elbir M, Topbaş ÖA, Bayad S, et al. DSM-5 İçin Yapılandırılmış Klinik Görüşmenin (SCID-5) Türkçeye Uyarlanması Ve Güvenilirliği Türk Psikiyatri Dergisi. 2019; 30: 51-6.

11. Goodman WK, Price LH, Rasmussen SA. The Yale- Brown Obsessive-Compulsive Scale:
Development, use, reliability, and validity. Arch Gen Psychiatry. 1989; 46: 1006- 16.

12. Karamustafalıoğlu $\mathrm{OK}$, Üçışık AM, Ulusoy $M$, Erkmen H. Yale-Brown Obsesyon-Kompulsiyon Derecelendirme Ölçeği Türkçe uyarlaması, Ulusal Psikiyatri Kongresi Program ve Bildiri Özetleri Kitabı Savaş Ofset. 1993; 86.

13. Nijenhuis ER, Van der Hart O, Kruger K. The psychometric characteristics of the Traumatic Experiences Checklist (TEC): First findings among psychiatric outpatients. Clinical Psychology \& Psychotherapy: An International Journal of Theory \& Practice. 2002; 9: 200-10.

14. Şar V. Travmatik Yaşantılar Ölçeği (TEC)-Türkçe Versiyonu. 2000. Erişim Tarihi: 15.02.2018 http://www.vedatsar.com/psikiyatrik-olcekler/

15. Beck AT, Ward CH, Mendelson M, Mock J, Erbaugh J. An inventory for measuring depression. Arch Gen Psychiatry. 1961; 4: 561-71.

16. Hisli N. Beck Depresyon Envanterinin Geçerliği Üzerine Bir Çalışma. Psikoloji Dergisi. 1989; 22: 118-26.

17. Yurdakök K. Çocuk istismar ve ihmali, tanım ve risk faktörleri. Katkı Pediatri Dergisi, 2010; 32: 53746.

18. Carr CP, Martins CM, Stingel AM, Lemgruber VB, Juruena MF. The role of early life stress in adult psychiatric disorders: a systematic review according to childhood trauma subtypes. J Nerv Ment Dis. 2013; 201: 1007-20.

19. Heim C, Nemeroff CB. The role of childhood trauma in the neurobiology of mood and anxiety disorders: preclinical and clinical studies. Biological psychiatry. 2001; 49: 1023-39.

20. Herrenkohl TI, Hong S, Klika JB, Herrenkohl RC, Russo MJ. Developmental impacts of child abuse and neglect related to adult mental health, substance use, and physical health. Journal of Family Violence. 2013; 28: 191-9.

21. Khosravani V, Kamali Z, Jamaati Ardakani R, Samimi Ardestani M. The relation of childhood trauma to suicide ideation in patients suffering from obsessive-compulsive disorder with lifetime suicide attempts. Psychiatry Res. 2017; 255: 139-45. 
22. Aker T. Önder E. Psychological trauma and its consequences. Psikolojik Travma ve Sonuçları. İstanbul: 5US Yayınları. 2013; 105-20.

23. Çelikel H, Beşiroğlu L.Non-clinical samples; childhood traumatic experiences, dissociation and obsessive-compulsive symptoms. Anadolu Psikiyatri Dergisi. 2008; 9: 75-83.

24. Webb M, Otto Whitmer KJ. Abuse history, world assumptions, and religious problem solving. Journal for the Scientific Study of Religion. 2001; 40: 445-53.

25. Salkovskis P, Shafran R, Rachman S, Freeston $\mathrm{MH}$. Multiple pathways to inflated responsibility beliefs in obsessional problems: Possible origins and implications for therapy and research. Behaviour Research and Therapy. 1999; 37: 1055-72.

26. Tatlı M, Cetinkaya O, Maner F. Evaluation of Relationship between Obsessive-compulsive Disorder and Dissociative Experiences. Clin Psychopharmacol Neurosci. 2018; 16: 161-7.
27. Çamlı K, Türkçapar H, Sargın E. Reaktif ve Otojen Özellikler Gösteren Obsesif Kompulsif Bozuklukta İçgörü, Bilişsel İçgörü ve Sosyodemografik Özellikler. JCBPR. 2012; 1: 28-35.

28. Beşiroğlu L. Obsesif kompulsif bozuklukta fenomenoloji: Tedavi yanıtı için önemli mi? Farklı Yönleriyle Obsesif Kompulsif Bozukluğun Tedavisi. Pskiyatride Güncel. 2014; 4: 222-5.

29. Lee HJ, Kwon SM. Two different types of obsession: Autogenous obsessions and reactive obsessions. Behav Res Ther. 2003; 41: 11- 29.

30. Grisham JR, Fullana MA, Mataix-Cols D, et al. Risk factors prospectively associated with adult obsessive-compulsive symptom dimensions and obsessive-compulsive disorder. Psychological Medicine. 2011; 41: 2495-506. 